\title{
Glucose Homeostasis in Preterm Rhesus Monkey Neonates
}

\author{
W. GEOFFREY SHERIWOOD, ${ }^{(3 \pi)}$ DONALD E. HILL, AND GRAHAM W. CHANCE \\ Perinatal Growth and Development Programme, Research Institute, and Department of Pacediatrics, Division of \\ Perinatology, The Hospital for Sick Children, Toronto, Ontario, Canada
}

\begin{abstract}
Summary
Response to a primed glucose infusion $(0.5 \mathrm{~g} / \mathrm{kg}$ injected over $3 \mathrm{~min}$ and $8 \mathrm{mg} / \mathrm{kg} / \mathrm{min}$ infused for $3 \mathrm{hr}$ ) was studied in $5 \mathrm{term}$ and 11 preterm rhesus monkey neonates $2-3 \mathrm{hr}$ after delivery by cesarian section. The glucose challenge perturbed a steady state glucose specific activity achieved in the previous $100 \mathrm{~min}$ by a primed trace infusion of $\left.2-I^{3} \mathrm{H}\right] \mathrm{glucose}(6 \mu \mathrm{Ci}$ and $0.2 \mu \mathrm{Ci} / \mathrm{min})$. This allowed the determination of changes in endogenous glucose turnover in response to exogenous glucose in the immediate newborn period.

With glucose challenge, the 5 term animals and 6 of the 11 preterm animals developed a new steady state glucose concentration $(80-100 \mathrm{ml} / \mathrm{dl})$. Coincident with this was a marked reduction in endogenous hepatic glucose output and a moderate increase in peripheral glucose utilization as measured by the tracer methodology. In contrast, the other five preterm monkeys developed hyperglycemia upon glucose challenge (190-210 mg/ d). All groups had similar glucose-stimulated insulin release which peaked after $60 \mathrm{~min}$ of glucose infusion. However, in comparison to the other groups, the group that was to develop hyperglycemia exhibited: (l) lower basal insulin and higher basal glucose values; (2) no suppression of endogenous hepatic glucose output or lipolysis despite glucose-stimulated insulin release; (3) lower birth weight and gestational age, and increased eventual mortality. Hypoxia was not evident in any group as evidenced by clinical signs and decreasing lactate/ pyruvate ratios during the glucose infusions.
\end{abstract}

\section{Speculation}

The inability of certain preterm rhesus monkeys to maintain normoglycemia, but rather to develop hyperglycemia in the face of a glucose infusion might be related to inappropriate adrenergic activity unrelated to either hypoxia or hypothermic stress. This represents an animal model for the further study of hyperglycemia seen in certain human preterm neonates.

The development of metabolic control of postnatal energy homeostasis remains an enigmatic area in perinatal medicine. Neonatal hypoglycemia has received much attention because of its association with neurologic symptomatology and consequent cerebral damage. As a result of technologic advances very low birth weight neonates are surviving in increasing numbers. A high incidence of hyperglycemia (blood glucose values greater than $125 \mathrm{mg} / 100 \mathrm{ml}$ ) has been reported when glucose is administered either orally or intravenously in quantities that would be well tolerated and maintain euglycemia in most neonates $(5,6)$. Ethical, rather than technical, considerations rightly prevent comprehensive investigation of the maturation of glucose homeostasis in these infants.

Reports of hyperglycemia in very low birth weight neonates indicate a nonspecific association with increased mortality $(4,6$, $9,22,28)$. However, few series have excluded the recognized causes of hyperglyeemia in the neonate such as sepsis (27) and hypoxia (2), which are themselves associated with increased mortality. Many very low birth weight neonates experience hyperglycemia where no immediate etiologic factor can be implicated. Such neonates represent a dilemma in clinical management, namely, the provision of continued nutritional support in the presence of hyperglycemia with resultant osmotic diuresis and water-electrolyte imbalance.

Knowledge of underlying mechanisms is essential in order to rationalize the clinical management. The purpose of this study was to develop a primate model and apply a study protocol to the prematurely delivered rhesus monkey neonate in order to investigate postnatal glucose homeostasis utilizing radioactive tracer kinetic methodology.

\section{METHODS}

\section{PROCEDURES}

Our primate population was derived from the breeding colony maintained in the Psychology Department of the University of Waterloo, Ontario, where conception was timed to \pm 1 day. Sixteen rhesus monkeys (Macaca mulatta) were delivered by cesarian section under ketamine- $\mathrm{HCl}$ anesthesia (29): 5 near term (1.58 days) and 11 prematurely (138-1+2) days). Others have shown that the increase in the amniotic fluid lecithinsphingomyelin ratio in rhesus monkeys commenced at around 140 days of gestation (11). All of our preterm neonates exhibited clinical signs of pulmonary immaturity. The mothers were calorie deprived overnight but allowed water ad libitum. During anesthesia, a slow intravenous infusion of $0.9 \%$ sodium chloride solution was administered. The average time from initiation of maternal anesthesia to delivery was $2(0)-25 \mathrm{~min}$.

Umbilical arterial and venous catheters (30) were placed and secured in all the neonates immediately after delivery. All of the preterm newborns underwent endotracheal intubation with suitably sized tubes (31). Ventilatory support was provided in order to maintain good clinical oxygenation as indicated by pink buccal mucosae. This was achieved by an increased inspiratory oxygen concentration $\left(\mathrm{FI}_{\mathrm{O}_{2}}\right)$ in the range of $0.3-0.5$ and the application of continuous airways distending pressure in the range of $5-8 \mathrm{~cm}$ water. In those preterm neonates who exhibited some irregularity in respiratory pattern with a tendency towards periods of apnea, prophylactic intermittent positive pressure ventilation was provided (32). This was required only during the first $2 \mathrm{hr}$ of life. Adequate rib cage movement was achieved with inspiratory pressure in the range of $20-25 \mathrm{~cm}$ water and inspiratory rate in the range of $4(0-50 / \mathrm{min}$. The small blood volume of these neonates prohibited intermittent monitoring of blood $\mathrm{pH}, \mathrm{pO}_{2}$, and $\mathrm{pCO}_{2}$. Catheterization and intubation were completed within 5 min of severance of the umbilical cord. The catheters were maintained patent with a slow saline infusion delivered by constant infusion pump. These procedures were performed under an infrared radiant heat warmer. The newborns were then placed 
immediately in a prewarmed incubator in which the temperature was maintained at $36^{\circ}$. Neither core nor skin temperature was directly monitored.

\section{STUDY PROTOCOL}

The newborns were allowed to achieve clinical stability for 2-3 hr. Then a primed infusion of $2-\left[{ }^{3} \mathrm{H}\right]$ glucose of high specific activity $(6 \mu \mathrm{Ci}$ followed by $0.2 \mu \mathrm{Ci} / \mathrm{min})(33)$ in normal saline was administered via the umbilical venous catheter. After 100 min of isotope infusion, a primed infusion of "cold" glucose was added to the intravenous administration. Glucose dosage was $9.5 \mathrm{~g} / \mathrm{kg}$ injected over $3 \mathrm{~min}$ followed immediately by $8 \mathrm{mg} / \mathrm{kg} /$ min infused for $180 \mathrm{~min}$. Throughout, the rate of fluid administered was maintained in the range of $80-120 \mathrm{ml} / \mathrm{kg} / 2+\mathrm{hr}(3.3-$ $5.0 \mathrm{ml} / \mathrm{kg} / \mathrm{hr})$.

Heparinized blood samples were obtained serially from the umbilical artery catheter. The total blood volume was depeleted by less than $5 \%$ during any single study.

\section{LABORATORY METHODS}

Each sample was assayed for blood glucose (14), plasma insulin (26), plasma free fatty acids (16), blood lactate, pyruvate, and 3-hydroxybutyrate (3). Glucose specific activity was measured in a 100- $\mu$ l aliquot of the filtrate obtained by deproteinizing and equivolume of whole blood with $0.6 \mathrm{M}$ perchloric acid. The aliquot was evaporated to dryness in vacuo. The residue was redissolved in $100 \mu \mathrm{l}$ distilled water. Braly's solution was added before counting in a Beckman liquid scintillation counter. Appropriate blanks and standards were run for each study in order to allow for quench correction.

\section{CALCULATIONS}

With knowledge of tracer infusion rate and glucose specific activity, glucose turnover rate was calculated by the method of Stecle $(15,25)$ for the basal situation and at hourly intervals during the glucose-stimulated situation. It was expressed as endogenous hepatic glucose output or $R_{A}$ and peripheral glucose utilization or $R_{\mathrm{D}}$ in the units of milligrams of glucose per $k g$ per min.

\section{RESULTS}

Throughout this section, the results are presented as mean \pm 1 SE. There are no significant differences between groups $P_{1}$ and $T$ for blood glucose, insulin, intermediary metabolite, tracer kinetic, or cord blood data. Significant differences ( $P$ values), as determined by Student's $t$-test, are presented for the $P$. group in comparison to the $P_{1}$ group. The retrospective separation within the preterm newborn is based on the observation of two very different glyeemic responses to primed glucose infusions. That difference is extremely significant.

\section{BI.OOD GI.UCOSE DATA (FIG. 1)}

The patterns of blood glucose response to primed glucose infusion indicate that the 11 preterm newborns fall into two categories. Five, designated $P_{1}$, responded in a manner similar to five term newborns, designated $T$. The basal glucose concentrations were similar $61 \pm 8 \mathrm{mg} / \mathrm{dl}$ and $55 \pm 6 \mathrm{mg} / \mathrm{dl}$, respectively, and both groups developed a new glucose steady state glucose concentration in the range of $8(0-100) \mathrm{mg} / \mathrm{dl}$ after an initial peak following the priming dose of glucose. The other six preterm newborns, designated $P_{2}$, exhibited a higher basal glucose level, $80 \pm 1 \mathrm{mg} / \mathrm{dl}(P<0.005)$, and developed a new steady state glucose concentration in the range $190-210 \mathrm{mg} / \mathrm{dl}(P<0.005)$.

\section{PLASMA INSULIN DATA (FIG. 1)}

The basal insulin values for groups $P_{1}$ and $T$ were not significantly different, $16 \pm 4$ and $27 \pm 12 \mu \mathrm{U} / \mathrm{ml}$, respectively.
Group $P_{2}$ showed a significantly lower level, $4 \pm 2 \mu \mathrm{U} / \mathrm{ml}(P<$ $0.001)$. In all groups, the glucose-stimulated insulin release peaked to similar levels 60 min after commencement of the primed glucose infusion. The peak levels were $68 \pm 4,62 \pm 10$, and $47 \pm 7 \mu \mathrm{U} / \mathrm{ml}$ in groups $P_{1}, T$, and $P_{2}$, respectively (NS).

\section{INTERMEDIATE METABOLITE DATA (FIG. 2)}

The two groups of preterm neonates, $P_{1}$ and $P_{2}$, were compared in terms of free fatty acid and $\beta$-hydroxybutyrate levels. In the $P_{2}$ group the basal free fatty acid levels were higher, $0.58 \pm$ 0.09 versus $0.30 \pm 0.08 \mathrm{mM}(P<0.05)$, and were not suppressed despite glucose-stimulated insulin release. The levels rose marginally to $0.64 \pm 0.07 \mathrm{mM}$ after $60 \mathrm{~min}$ of glucose infusion in group $p_{2}$. Similar trends were found in the 3-hydroxybutyrate levels. The corresponding values for group $T$ were similar to those for group $P_{1}$.

The basal lactate values of groups $P_{1}$ and $P_{2}$ were $1.1 \pm 0.4$ $\mathrm{mM}$ and $1.7 \pm 0.7 \mathrm{mM}$, respectively. The corresponding blood pyruvate levels were $0.028 \pm 0.007$ and $0.032 \pm 0.006 \mathrm{mM}$; the

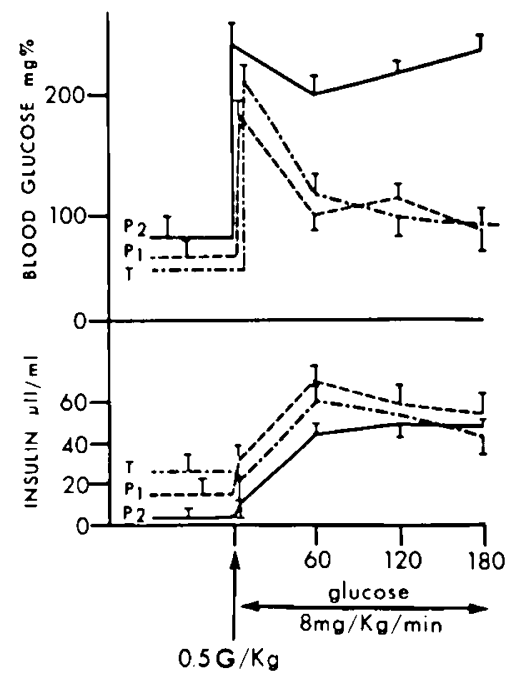

Fig. 1. Sequential changes in blood glucose and serum insulin values before and during primed glucose infusion. $T$ : term newborn (158 days); $P_{1}$ and $P_{2}$ : preterm neonates (around 140 days).

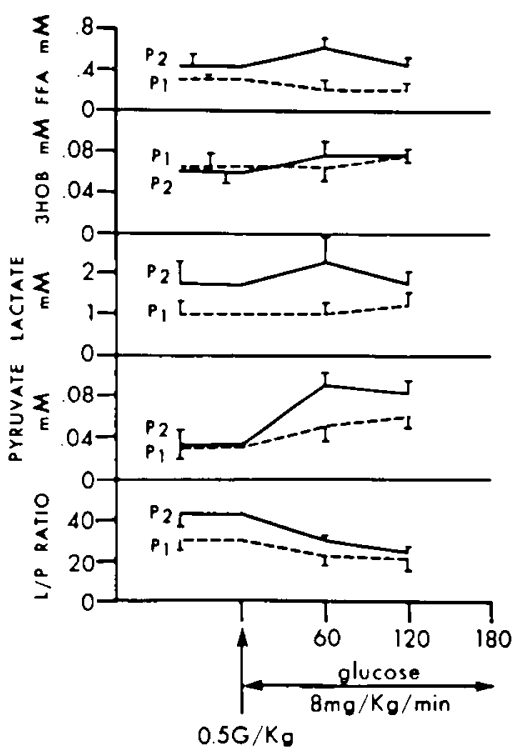

Fig. 2. Sequential changes in serum free fatty acids (FFA), 3-hydroxybutyrate $(3 H O B)$, lactate pyruvate, and lactate/pyruvate $(\mathrm{L} / \mathrm{P})$ ratio before and during primed glucose infusion. 
corresponding lactate/pyruvate molar ratios were $31 \pm 6$ and 42 \pm 7 . During the glucose challenge, the ratio progressively fell in all groups to a range of 15-20 as the blood lactate and blood pyruvate values rose. The corresponding values for group $T$ were similar to those for group $p_{1}$.

\section{TRACER KINETIC DATA (FIG. 3)}

In the basal steady state situation, the endogenous hepatic glucose output rate, $R_{A}$, was equal to the peripheral glucose utilization rate, $\mathrm{R}_{1}$. For groups $T, P_{1}$, and $P_{2}$, the basal glucose turnover rates were not statistically different; $5.4 \pm 0.9,6.2 \pm$ 0.7 , and $7.3 \pm 0.6 \mathrm{mg} / \mathrm{kg} / \mathrm{min}$. In all groups, $R_{1}$, increased to the range $9-12 \mathrm{mg} / \mathrm{kg} / \mathrm{min}$ during the glucose infusion. In groups $T$ and $P_{1}, \mathrm{R}_{\mathrm{A}}$ was diminished to negligible amounts during the glucose infusion. However, in group $P_{2}$ there was no significant diminution of $R_{A}$.

\section{CORD BL.OOD DATA}

The cord lactate values for groups $T, P_{1}$, and $P_{2}$ were $2.88 \pm$ $0.44,1.5 \pm 0.12$, and $2.6 \pm 0.67 \mathrm{mM}$, respectively. The corresponding pyruvate values were $0.072 \pm 0.020,0.048 \pm 0.018$, and $0.111 \pm 0.030 \mathrm{mM}$.

\section{STUDY GROUP CHARACTERISTICS (TABLE 1)}

Retrospective analysis of the newborns studied showed that the "hyperglycemic" preterm group $\left(P_{2}\right)$ exhibited a lower birth weight $(P<0.05)$, shorter gestational period $(P<0.05)$, and higher eventual mortality (NS) when compared to the other preterm group $\left(P_{1}\right)$. Characteristics for the full term control group $(T)$ are given for comparison.

\section{DISCUSSION}

Our data indicate that certain preterm rhesus monkey neonates develop hyperglycemia when challenged with intravenous glucose in the form of a primed infusion at the age of $2-3 \mathrm{hr}$ before exogenous caloric intake. In so doing, they resemble a group of human preterm neonates similarly challenged (22). However, other preterm rhesus monkey newborns respond to such a challenge in a manner resembling the response of term neonates. These groups, $T$, and $P_{1}$, develop a euglycemic steady state of glucose concentration in the range $80-100 \mathrm{mg} / \mathrm{dl} \mathrm{com}-$ pared to $190-210 \mathrm{mg} / \mathrm{dl}$ in the $P_{2}$ group.

We have found that this "hyperglycemic" group is characterized by: ( $l$ ) lower basal insulin concentration and higher basal glucose concentration; (2) unsuppressed, endogenous hepatic glucose output and lipolysis despite glucose-stimulated insulin release; (3) greater immaturity in terms of birth weight, gestation, and eventual mortality.

It appears that the factor, or factors, which caused hyperglycemia upon glucose challenge were operational before glucose administration. Stress was avoided as far as possible by treating each newborn monkey pre-, intra-, and postpartally in a manner to which every human "at risk" newborn should ideally be exposed.

Prepartal and intrapartal stress was avoided by minimizing the duration of maternal anesthesia, and operative delivery time with the mother in the left lateral position. Although ketamine$\mathrm{HCl}$ is said to possess respiratory depressant action on the fetus (10), this was not so in our term neonates, who all breathed spontaneously. No data is available to suggest that ketamine has an adverse effect on carbohydrate metabolism. The similarity of cord lactate levels in all three groups make it unlikely that the neonates suffered from intrauterine hypoxic stress.

Hypothermia during the immediate postpartal period was minimized by performing all procedures, i.e., intubation and catheterization, rapidly under a warming infrared lamp and placing the neonates in isolettes maintained at $36^{\circ}$. Data on thermoneutral environments are not available for newborn rhe-

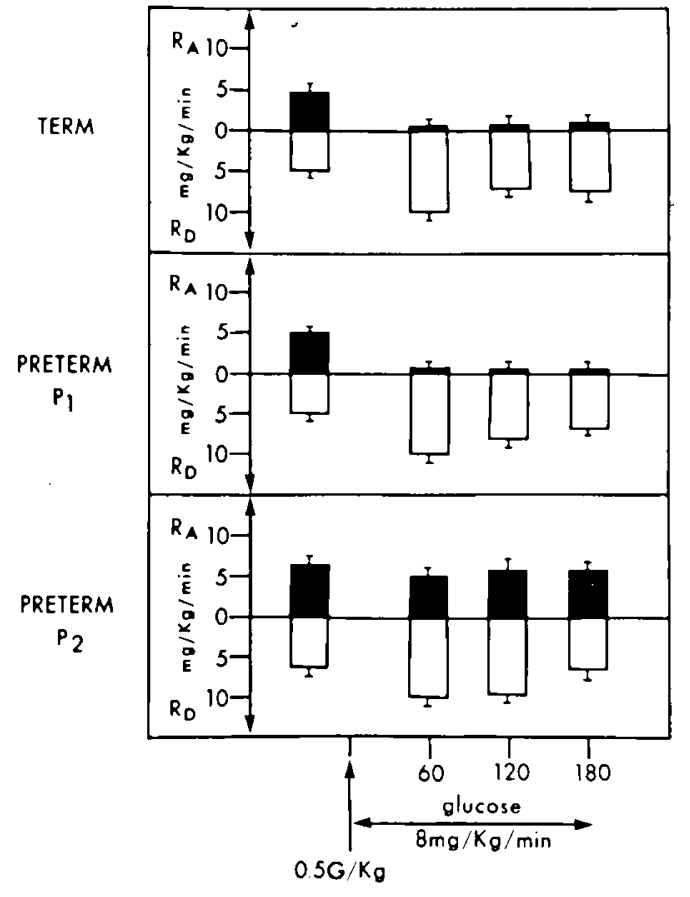

Fig. 3. Sequential changes in endogenous hepatic glucose output $\left(R_{A}\right)$ and peripheral utilization rate of glucose $\left(R_{l}\right)$ before and during primed glucose infusion.

Table 1. Birth weight, gestation, and mortality statistics of groups $T, P_{1}$, and $P_{2}$

\begin{tabular}{llll}
\hline & & \multicolumn{1}{c}{ Preterm, } & \multicolumn{1}{c}{ Preterm, } \\
\hline Birth weight, $g$ & $440 \pm 20$ & \multicolumn{1}{c}{$P_{1}$} & \multicolumn{1}{c}{$P_{2}$} \\
Gestation, days & $158 \pm 1$ & $143 \pm 15$ & $341 \pm 22$ \\
Mortality, \% (ratio) & $0 \%(0 / 5)$ & $40 \%(2 / 5)$ & $140 \pm 1$ \\
\hline
\end{tabular}

sus monkeys. Double walled isolettes and high humidity were not used. Technigues to minimize cold stress were similar for incubator care of human neonates, but we recognize that some heat loss may have occurred under these circumstances.

Hypoxia during the postpartal period, a recognized cause of hyperglycemia, cannot be implicated as evideneed by a decline in the lactate/pyruvate molar ratios during glucose infusion. A reduced cytosolic redox state, secondary to tissue hypoxia, would induce an increase in lactate relative to pyruvate concentration upon glucose challenge. Thus an elevation of the molar ratio would have occurred, had tissue hypoxia been manifest. Clinical observation during study confirmed adequate oxygenation in all newborns. Rather than tissue hypoxia, our data would suggest a relative deficiency in pyruvate oxidation at the dehy-' drogenase complex step.

Thus, we suggest that, in these neonates that develop hyperglycemia upon glucose challenge, the factors responsible are endogenous rather than exogenous in origin. Alternatively, certain preterm newborn might respond excessively and inappropriately to exogenous stimuli that in other preterm or term neonates do not evoke such response. The major exogenous stimuli referred to are pre- or intrapartal stress, and the postpartal stresses of hypothermia and hypoxia. It is of interest that these "hyperglycemia" neonates were of somewhat shorter gestational period and lower birth weight.

The study of perinatal glucose homeostasis comprises the study of maturation of several opposing hormonal, neural, metabolic and enzymatic systems. Any of these, individually or in combination, might be responsible for the "intolerance" to exogenous glucose seen in certain preterm neonates. However, the constellation of low basal insulin values and unsuppressed en- 
dogenous hepatic glucose output and lipolysis, despite glucosestimulated insulin release, when considered in combination, lead us to the speculation that the common basic etiology involves excessive adrenergic activity. Catecholamines reduce basal insulin secretion (13) and stimulate lipolysis $(19,21)$. The modulation of glucose turnover by the adrenergic system is more complicated. Diminution of hepatic glucose production is casued by epinephrine via a receptor classified as neither $\alpha$ nor $\beta$ type (23). Peripheral glucose utilization is not only inhibited by epinephrine, but also promoted by insulin, the release of which is enhanced via a $\beta$-receptor and is suppressed via an $\alpha$-receptor (23).

The tracer kinetic method employed in these studies involved the use of a continuous infusion of glucose tritiated in the 2carbon position. The validity of the use of this particular isotope for the study of glucose turnover has been tested $(15,25)$. However, such methodology does not allow for the differentiation of the relative contributions to endogenous hepatic glueose output of glycogenolysis and/or gluconeogenesis. In recent years, studies indicate that both the fetus and the newborn of several species are capable of gluconeogenesis $(1,7,18,20)$. Our studies also tend to refute earlier concepts of diminished gluconeogenic capabilities in the neonatal animal (8). Recent work on neonatal glycogen metabolism in the rhesus monkey suggests that the capacity of the synthetic component lags behind the capacity of the phosphorylase cascade component during development $(12,24)$. Recent studies on hepatic glycogen metabelism in the fetal and neonatal rat are of great interest. At term (22 days), glucose stimulates glyeogen synthetase activity and depresses glycogen phosphorylase activity. However, no depression of the phosphorylase activity accompanies the stimulated synthetic activity at 17 days of gestation. This was shown to be due to ongoing activity of the phosphatase responsible for converting the inactive to the active form of phosphorylase (17). Furthermore, unsuppressed endogenous hepatic glucose output during glucose infusions has also been observed recently in term lambs (7).

\section{CONCLUSION}

In conclusion, our studies indicate that certain preterm rhesus monkeys respond to glucose challenge in a manner different from other preterm and all term rhesus monkeys. We suggest that the etiology of the "hyperglycemic" intolerance is primarily endogenous in origin and appears to be related to a disturbance in hormonal, neural, and/or enzymatic regulatory factors. It would appear reasonable to investigate the modulation of the response to glucose challenge in a preterm monkey population with modification of the autonomic "milieu." This would proffer further insight into preterm glucose homeostasis. The application of such knowledge to the human situation might improve the nutritional support of the very low brith weight neonate.

\section{RIEIERENCIS AND NOTES}

1. Adam, P. A. J., Glazer, G., and Rogoff, F.: Glucose production in the newborn dog. I. Pediat. Res., 9: 816 (1975).

2. Baum, D., and Porte, D .. Jr,: Beta adenergic receptor dysunction in hypoxic inhibition of insulin release. Endocrinology. 98: 359 (1976).

3. Bergmeyer, H. U., and Bernt, E.: In: U. Bergmeyer: Methods of Enzymatic Analysis (Academic Press, New York. 196.5).

4. Bryan, M. H., Wei, P., Hamilton, J. R., Chance, G. W., and Swyer, P. R.: A controlled study of supplemental intravenous alimentation in newhorn less than $1300 \mathrm{~g}$. J. Pediat., 82: $942(1973)$

5. Chaivorarat, O., and Dweck, H. S.: Effect of prolonged continuous glucose infusion in preterm infants. Pediat. Res., 10: 406 (1976).

6. Chance, G. W.: Intravenous carbohydrate tolerance in infancy. In: H. H Bode and J. B. Warshaw: Parenteral Nutrition in Infancy and Childhood (Plenum Publishing Corp., New York, 1975).

7. Cowett, R. M., Susa, J. B., Oh, W., and Schwartz, R.: Endogenous glucose production during constant glucose infusion in the newhorn lamb. Pediat. Res., 10: 407 (1976).

8. Dawes, G. S.: Fetal and Neonatal Physiology: A Comparative Study of the Changes at Birth, Chapt. 1 (Year Book Publishers, Chicago, 1968).

9. Dweck, H. S., and Cassady, G.: Glucose intolerance in infants of very low hirth weight. Pediatrics, 53: 189 (1974).

10. Ing. M., Bonica, J. J., Akamatsu, T. J., Berges, P. U., and Ueland, K. Respiratory depression in newborn monkeys at Caesarian section following ketamine administration. Brit. J. Anaesthesiol., 49: 917 (1975)

11. Fpstein, M. F., and Farrell, P. M.: The choline incorporation pathway: Primary mechanism for de novo synthesis in fetal primate lung. Pediat. Res., 9: 658 (1975).

12. Glinsmann, W. H., Eiser, H. J., Lynch, A., and Chez, R. A.: Glucose regulation by isolated near term fetal monkey liver. Pediat. Res., 9: 600 (1975).

13. Goodner, C. J., and Porte, D., Jr.: Determinants of basal insulin secretion in man. In: A. Fishman: laandbook of physiology, Section 7. Endocrinology. Vol. 1, Endocrine Pancreas, pp. 597-611 (The Williams \& Wilkins Co., Baltimore, 1975).

14. Kadish, A. M., Little, R. L., and Sterberg, J. C.: Beckman glucose analyser method. Clin. Chem., 14: 116 (1968).

15. Katz. J., Rostami, H., and Dunn, A.: Evaluation of glucose turnover, body mass and recycling with reversible and irreversible tracers. Biochem. J. 142: $161(1974)$.

16. I.aurell, S., and Tibbling, G.: Colorimetric microdetermination of free fatty acids in plasma. Clin. Chim. Acta. 16: 57 (1967).

17. Pines, M1., Bashan, N., and Meses, S. W.: Glucose effect on glyeogen synthetase and phosphorylase. FEBS Lett., 62: 301 (1976)

18. Robinson, B. H., and Oei, J.: The effect of premature delivery on the development of gluconeogenic enzymes in the guineat pig. Pediat. Res., 10. $819(1976)$.

19. Schiff, D., Stern, L.., and Leduc, J.: Chemical thermogenesis in newborn infants: Catecholamine excretion and the plasma non-esterified fatty acid response to cold exposure. Pediatrics, 37: 577 (1966).

20. Schwartz. A. L.: Hormonal regulation of glucose production in human fetal liver. (Ph.D. thesis, Case Western Reserve, 1974).

21. Smith, R. IE.. and Horwitz, B. A.: Brown fat and thermogenesis. Physiol. Rev., 49: 330 (1964)

22. Sherwood, IV. G., and Chance, G. W.: The development of the biphasic insulin response to glucose in the very low hirth weight neonate. (In preparation.)

23. Shikama, H., and Ui, M1.: Adrenergic receptor and epinephrine induced hypoglyecmia and glucose tolerance. Amer. J. Physiol. 229: 962 (1975).

24. Sparks, J. W., Lynch, A., Chez, R. A., and Glinsmann, W. H.: Glycogen regulation in isolated perfused near term monkey liver. Pediat. Res., $l 0: 51$ (1976).

25. Vranic. M1.: Tracer methodology and glucose turnover (Report on Conference). Fed. Proc.. 3.3: 18.3 (1974)

26. Wilson. R. B., and Martin, J. M.: Radioimmunoassay of plasma insulin in dogs and monkeys: Application of the dextran-coated charcoal separation method. Can. J. Comp. Med.. 33: 264 (1969).

27. Yeung. C. Y.. Vwy, L., and Yeung. MI.: Glucose disappearance rate in neonatal infection. J. Pediat.. 82: 486 (1973).

28. Zarif, M., Pildes, R., and Vidyasagar, D.: Insulin and growth hormone responses in neonatil hyperglycemia Diaberes, 25: 428 (1976).

29. Ketolar (ketamine-HCl), Parke Davis \& Co. Ltd.

30. Argyll umbilical arterial catheter, $3.5 \mathrm{~F}$. Catalogue no. MAR 160)2-3; manufactured by Sherwood. N11.

31. Sterilon feeding tube, 8 F seamless, Division of Dart Industries. Inc.

32. Puritan Bennett PR 2 ventilator, kindly loaned by Puritan Bennett Company Lid.,

33. Amersham Searle Radiopharmaceuticals, Catalog no. TRA 361, specific activity $500 \mathrm{mCi} / \mathrm{mmol}$

34. The athors wish to express their gratitude for the excellent technical assistance of Mrs. Susan Mayes, Mrs. E. Friere, and Mr. D. DiBattista.

35. W. G. Sherwood was recipient of a Medical Research Council Fellowship.

36. This study was supported by the Medical Research Council of Canada, Cirant MA 5127.

37. Requests for reprints should be addressed to: W'. G. Sherwood, M.D., Research Institute, The Hospital for Sick Chiklsen. 555 University Ave. Toronto, Ontario M5G IX8 (Canada).

38. Received for publication September 1,1976

39. Accepted for publication February 2. 1977. 